\title{
A nove, putative MEK kinase controls developmental timing and spatial patterning in D ictyostelium and is regulated by ubiquitin-mediated protein degradation
}

\author{
Chang Y. Chung, T.B.K. Reddy, Kemin Zhou, and Richard A. Firte ${ }^{\mathbf{1}}$ \\ Department of Biology, Center for Molecular Genetics, University of California, San Diego, \\ La Jolla, California 92093-0634 USA
}

\begin{abstract}
We have identified a developmentally regulated, putative MEK kinase (MEKKa) that contains an F-box and WD40 repeats and plays a complex role in regulating cell-type differentiation and spatial patterning. Cells deficient in MEKKa develop precociously and exhibit abnormal cell-type patteming with an increase in one of the prestalk compartments (pstO), a concomitant reduction in the prespore domain, and a loss of the sharp compartment boundaries, resulting in overlapping prestalk and prespore domains. Overexpression of MEKKa or MEKKa lacking the WD40 repeats results in very delayed development and a severe loss of compartment boundaries. Prespore and prestalk cells are interspersed throughout the slug. Analysis of chimeric organisms suggests that MEKK $\alpha$ function is required for the proper induction and maintenance of prespore cell differentiation. We show that the WD40 repeats target MEKK $\alpha$ to the cortical region of the cell, wherees the F-box/WD40 repeats direct ubiquitin-mediated MEKK $\alpha$ degradation. We identify a UBC and a UBP (ubiquitin hydrolase) that interact with the F-box/WD40 repeats. Our findings indicate that cells lacking the ubiquitin hydrolase have phenotypes similar to those of MEKK $\alpha$ null (mekk $\alpha$ ) cells, further supporting a direct genetic and biochemical interaction between MEKK $\alpha$, the UBC, and the UBP. We demonstrate that UBC and UBP differentially control MEKK $\alpha$ ubiquitination/deubiquitination and degradation through the F-box/WD40 repeats in a cell-type-specific and temporally regulated manner. Our results represent a novel mechanism that includes targeted protein degradation by which MAP kinase cascade components can be controlled. More importantly, our findings suggest a new paradigm of spatial and temporal control of the kinase activity controlling spatial patteming during multicellular development, which parallels the temporally regulated degradation of proteins required for cell-cycle progression.
\end{abstract}

[Key Words: Dictyostelium; MEK kinase; ubiquitination; WD40 repeats; F-box; devel opment]

Received July 13, 1998; revised version accepted September 22, 1998.

In Dictyostelium, multicellular devel opment is initiated by the chemotactic aggregation of up to $10^{5}$ cells to form a fruiting body containing a sorus of spores on a slender stalk held up by a basal disk (Loomis 1982). Aggregation is regulated through nanomolar CAMP pulses acting via pathways controlled through $\mathrm{G}$ protein-coupled, serpentine cell-surface receptors (cARs; Firtel 1995; Chen et al . 1996). As the mound forms, an increase in the level of extracellular CAM P is thought to activate a second signaling pathway that results in the induction of the postaggregative genes, including the transcription factor GBF and a transcriptional cascade that leads to cell-type dif-

${ }^{1}$ Corresponding author.

E-MAIL rafirte@ @ucsd.edu; FAX (619) 534-7073. ferentiation (A be et al. 1994; Schnitzler et al . 1994, 1995; Early et al. 1995; Firtel 1995, 1996; Ginsburg et al. 1995; Williams 1995). The newly formed prestalk and prespore cells then sort, producing a multicellular organism with a defined spatial pattern organized along the anteriorposterior axis.

A major question in developmental biology is how cells control their position and developmental state within a multicellular organism. Dictyostelium is an excellent system in which to examine this question, as cells do not become fully committed until culmination, when the fruiting body is formed. Wild-type Dictyostelium organisms can vary in size by $>3$ orders of magnitude, yet the spatial patterning of the cell types remains constant (Loomis 1993; Firtel 1995; Williams 1995). Recently, a number of genes have been shown to 
play important roles in controlling cell-type proportioning and spatial patterning in Dictyostelium. The homeobox-containing gene Wariai functions to control the respective sizes of the pstO and prespore domains via a cell nonautonomous pathway ( $\mathrm{H}$ an and Firtel 1998). Disruption of Wariai leads to a more than doubling of the pstO compartment, with a concomitant decrease in the prespore domain. Null mutants in the cAMP receptor CAR4, which is expressed during multicellular development, or the RIN G-finger/leucine zipper adaptor protein result in an increase in prespore gene expression and abnormal spatial patterning. Overexpression of rZIP leads to enhanced prestalk expression and reduced prespore expression (Balint-Kurti et al. 1997; Ginsburg and Kimmel 1997). cAR4 is thought to function by negatively regulating GSK3 activity, which is required for prespore cell differentiation, and functions antagonistically on pathways controlled by CAR 1 and CAR3, positive regulators of GSK3 (Harwood et al. 1995; Ginsburg and Kimmel 1997). A Dictyostelium STAT protein, Dd-STAT, regulates the spatial pattern of expression of the prestalk/stalk-specific gene ecmB and the differentiation of prestalk to stalk cells during culmination (Kawata et al. 1997; Araki et al. 1998; S. M ohanty, K.A. Jermyn, A. Early, A. Ceccarelli, T. Kawata, J.G. Williams, and R.A. Firtel, in prep.).

In this paper, we describe a new regulatory pathway including MEKK $\alpha$ that controls developmental timing and spatial patterning. We show that MEKK $\alpha$ is essential for pstO and prespore patterning: mekk $\alpha$ null cells or cells overexpressing a dominant-negative form of MEKK $\alpha$ develop rapidly, exhibit increased pstO and decreased prespore domains, and have a propensity to become prestalk cells in chimeras with wild-type cells. Overexpression of MEKK $\alpha$ or MEKK $\alpha$ lacking the WD 40 repeats results in very del ayed devel opment and a loss of the discrete cell-type compartments. The F-box and WD40 repeats of MEKK $\alpha$ control the subcellular localization and a cell-type-specific and temporal ly regulated degradation via differential ubiquitination by a developmental ly regulated UBP and a UBC. The spatial and temporal regulation of the stability of a MEKK represents a novel mechanism by which F-boxes and components of the ubiquitination pathway can function to control spatial patterning and developmental timing, the latter of which may have direct paral lels to the regulation of cellcycle components.

\section{Results}

Cloning and primary structure of the MEKK $\alpha$

MEKK $\alpha$ was identified in a PCR screen for MEKKs. Using one of the PCR products as a probe, a CDNA library was screened and cDNA clones were isolated and sequenced. Analysis of the derived amino acid sequence of a full-length CDN A clone revealed that the gene encodes a putative MEKK (MEK kinase) designated MEKK $\alpha$ (Fig. $1 A$ ) with very high sequence homology to MEKKs from vertebrates, yeast, and plants (Fig. 1B). MEKK $\alpha$ has a short amino-terminal, potential regulatory domain. In addition, MEKK $\alpha$ has a carboxy-terminal domain containing a conserved F-box (Fig. 1C) with five WD40 repeats that are most related to those of MET30 (Thomas et al. 1995). The F-box, originally identified in yeast cyclin $\mathrm{F}$ and other cell-cycle regulating proteins (Bai et al. 1996), is thought to play an important role in regulating protein stability by targeting the protein for degradation via ubiquitin-dependent proteolysis.

RNA blot analysis indicates that MEKK $\alpha$ encodes a single developmentally regulated transcript $(3.7 \mathrm{~kb})$ that is not detectabl e in vegetative cells and is induced during early development, with the highest expression during the multicellular stages (Fig. 2A).

MEKK $\alpha$ regulates morphogenesis

and developmental timing

To examine the potential function of $M E K K \alpha$, we cre ated a mekk $\alpha$ null (mekk $\alpha$ ) strain (see Materials and M ethods). mekk $\alpha^{-}$cells aggregated with normal timing (data not shown) but developed more rapidly than wildtype cells during the multicellular stages, producing fruiting bodies at $18 \mathrm{hr}$ compared to $24-26 \mathrm{hr}$ for wildtype strains (Fig. 2B). The fruiting bodies had smaller sori (spore heads) and longer stalks than in wild-type strains, indicating fewer spores. A putative dominant-negative MEKK $\alpha$ was created by mutating the 199 Iysine residue in the putative ATP-binding site of the kinase domain to alanine $\left(\mathrm{MEKK} \alpha^{\mathrm{K} 199 \mathrm{~A}}\right.$ ) to create a MEKK $\alpha$ that is expected to lack kinase activity. Cells constitutively expressing $M E K K \alpha^{K 199 A}$ from the Act15 promoter exhibited two devel opmental abnormal ities similar to mekk $\alpha$ null cells. MEKK $\alpha^{\mathrm{K} 199 \mathrm{~A}}$-expressing cells showed precocious devel opment, forming fruiting bodies $\sim 5 \mathrm{hr}$ earlier than wild-type strains. There was a significant reduction in the number of spores ( $15 \%$ of wild type), suggesting that MEKK $\alpha$ was required for efficient prespore/spore-cell differentiation. By $36 \mathrm{hr}$, thesporemass (sorus) was gl assy and contained predominantly water (Fig. 2B). The stronger morphological phenotype of the MEKK $\alpha^{\mathrm{K} 199 \mathrm{~A}}$-expressing cells compared to mek $\alpha^{-}$cells suggests a redundancy in the MEKK $\alpha$ part of the pathway that is blocked by $M E K K \alpha^{K 199 A}$ and/ or may be caused by the sequestering of components required for multiple pathways that function to mediate prespore/spore-cell differentiation.

In contrast, cells overexpressing MEKK $\alpha$ or $M E K K \alpha \Delta W D$ (MEKK $\alpha$ in which the WD40 repeats are deleted) from the Act15 promoter exhi bited very delayed development, with up to $50 \%$ of the aggregates arresting at the mound stage (Fig. 2C). The aggregates that developed further did not form slugs until $\sim 24 \mathrm{hr}$, and these slugs migrated for an extended period of time before culminating $(\sim 36 \mathrm{hr} ;$ Fig. $2 \mathrm{C})$. These results suggest that the $M E K K \alpha$ overexpressors were impai red in proceeding past the mound stage and defective in the initiation of culmination. Moreover, MEKK $\alpha \Delta W^{O E}$ cells that developed further showed very abnormal morphogenesis (Fig. 2C). These overexpression defects appear to result from defects in prespore cells because expression of either 
$\mathbf{A}$

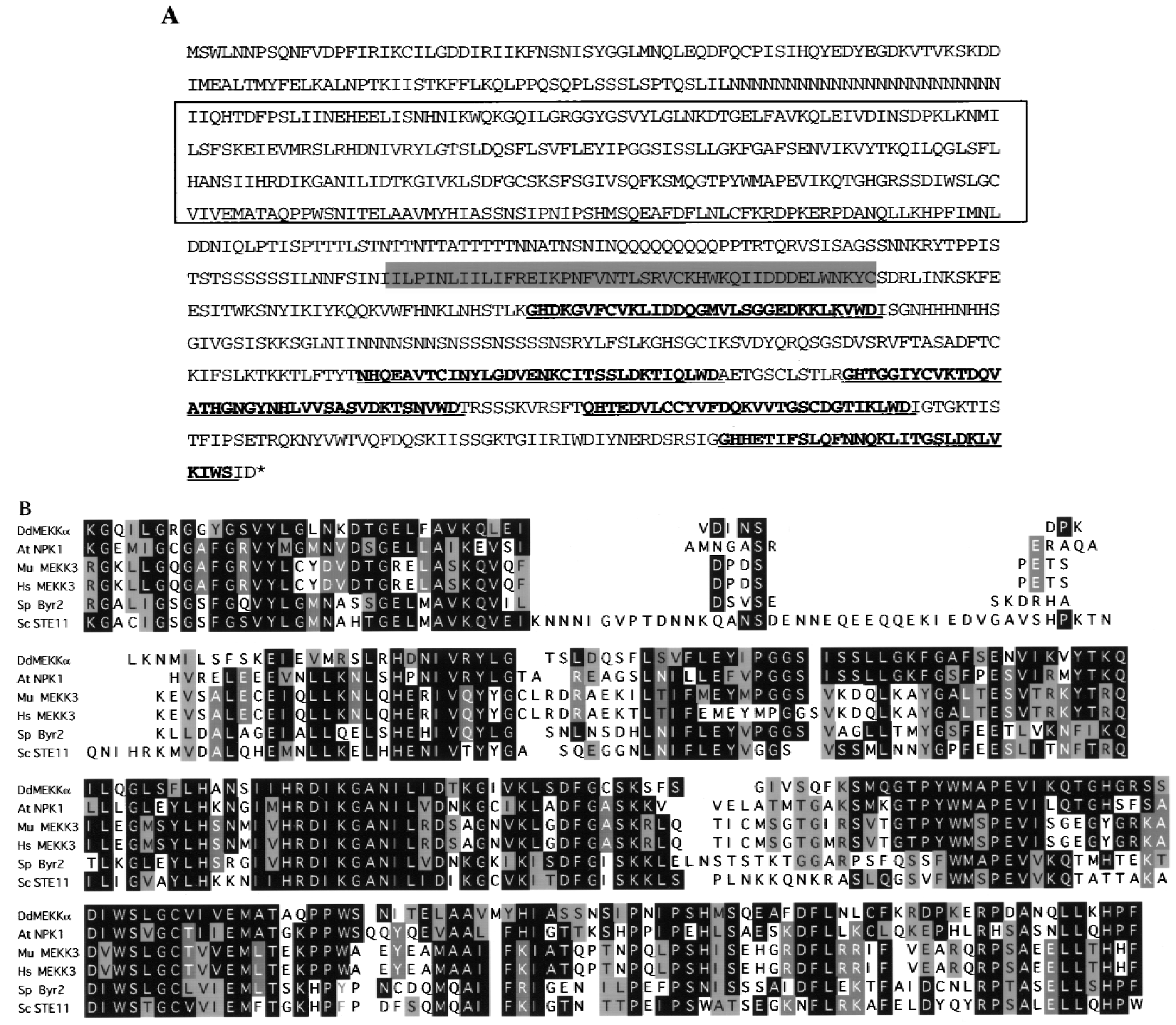

$\mathrm{C}$

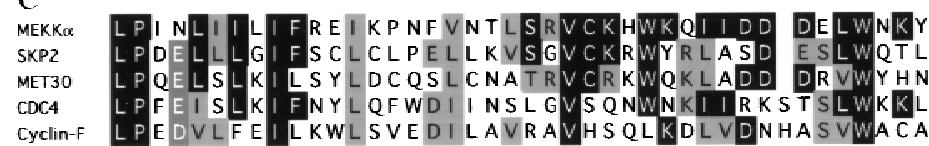

Figure 1. Deduced sequence of MEKK $\alpha$. (A) The CDN A clone, MEKK $\alpha 3-1$, has an insert of 2922 nucleotides and contains the entire $\mathrm{MEKK} \alpha$ ORF. The boxed regi on shows the conserved kinase domain. The hatched region (residues 523-563) shows the F-box sequence. The bold and underlined sequences indicate the position of five predicted $\beta$-transducin (WD40) repeats. (B) Amino acid sequence comparison of the kinase domain of MEKK $\alpha$ with MEKKs from a variety of organisms. A rabidopsis thaliana N PK1 (A48084); murine MEKK3 (U 43187); human M EKK3 (U 78876); Schizosaccharomyces pombe Byr2 (P28829); Saccharomyces cerevisiae STE11 (X53431); (C) Comparison of F-box sequence of MEKK $\alpha$ with the F-box sequences of other proteins such as human Cyclin F, human Skp2, Saccharomyces cerevisiae MET 30, and CDC4.

$M E K K \alpha$ or MEKK $\alpha \Delta W D$ from the SP60 prespore-specific promoter, but not from the ecmAO prestalk-specific promoter, results in delayed development and abnormal morphogenesis (data not shown).

We examined the effect of overexpressing the F-box motif and WD40 repeats at high levels from the Act15 promoter, which might disrupt the function of the Fbox/WD40 repeats of the endogenous MEKK $\alpha$. These overexpressor strains exhibited very delayed development, with $<40 \%$ of cells proceeding through development (data not shown). The sori of the fruiting bodies were severely deformed (Fig. 2B) and contained only $10 \%$ of the heat- and detergent-resistant spores found in wildtype strains (data not shown). These results suggest that MEKK $\alpha$ plays an important role in regulating prespore cell-type differentiation. 

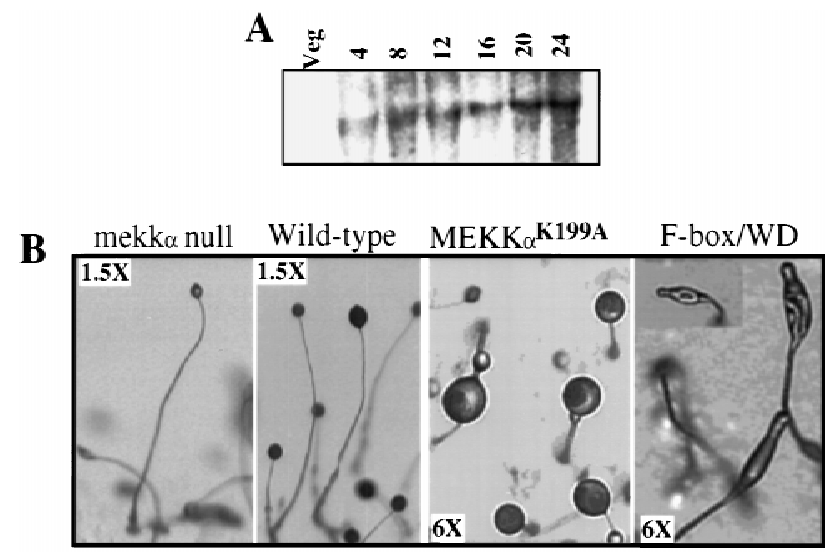

C

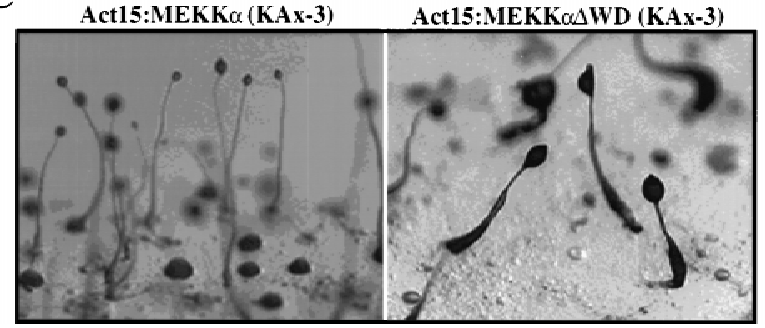

Figure 2. Analysis of the expression of the MEKK $\alpha$ gene during growth and development and the phenotype of MEKK $\alpha$ mutants. (A) Devel opmental RN A blot of MEKK $\alpha$ expression. Time in development is shown. (Veg) Vegetative cells. (B) Terminal phenotypes of mekk $\alpha^{-}$and wild-type cells and cells overexpressing the F-box/WD40 or MEKK $\alpha^{\mathrm{K} 199 \mathrm{~A}}$. The values in the boxes are magnifications. mek $\alpha^{-}$cells produce mature fruiting bodies that have smaller sori and longer stalks than mature wild-type fruiting bodies. Time of photographs: wild-type cells, $26 \mathrm{hr} ;$ mekk $\alpha^{-}$cells, $18 \mathrm{hr}$; MEKK $\alpha^{\mathrm{K} 199 \mathrm{~A}}$-expressing cells, $36 \mathrm{hr}$ (fruiting body formed at $18 \mathrm{hr}$, photograph shows glassy sori); cells overexpressing F-box/WD40 repeats, 36 hr. (C) Developmental morphology of cells overexpressing Act15/MEKK $\alpha$ or Act15/M EKK $\alpha \Delta$, which lacks WD 40 repeats. Both M EKK $\alpha$ and MEKK $\alpha \Delta$ WD overexpression cause very delayed development and many of the cells are arrested at the mound stage as seen in the MEKK $\alpha^{\mathrm{OE}}$ image. The mature fruiting bodies have smaller sori than wild type. Photographs taken at $36 \mathrm{hr}$. N ote the numerous mounds in the photograph of $\mathrm{MEKK} \alpha{ }^{\mathrm{OE}}$ cells. These are aggregates that arrested at this stage.

\section{MEKK $\alpha$ regulates spatial patterning}

To examine a role for MEKK $\alpha$ in regulating cell-type differentiation, cell-type-specific markers in MEKK $\alpha$ mutant strains were analyzed by developmental RNA blot analysis (Fig. 3). Consistent with their precocious development during the multicellular stages, mekk $\alpha^{-}$ cells exhibited a precocious peak of expression of the prestalk-specific genes ecmA and ecmB and the sporespecific marker SpiA. Compared to wild-type cells, the level of ecmA expression in mekk $\alpha^{-}$cells showed a slight, but reproducible increase, whereas the level of expression of the spore marker SpiA was reduced (Fig. $3 A$ ). This is consistent with a longer stalk and smaller sorus in mekk $\alpha^{-}$fruiting bodies. These effects were even more pronounced in cells expressing MEKK $\alpha^{\mathrm{K} 199 \mathrm{~A}}$, con- sistent with this strain's more severe developmental phenotype. In these cells, ecmA and ecmB exhibited an elevated and precocious expression. Expression of the prespore and spore-specific markers SP60/cotC and SpiA was reduced and the time of expression was earlier than in wild-type cells, consistent with the more rapid development of this strain. Overexpression of either $M E K K \alpha$ or $M E K K \alpha \Delta W D$ resulted in an extended period of expression of both the prestal $\mathrm{k}$ gene ecmA and the prespore gene SP60/ cotC, as would be expected from the extended period of slug migration in these strains (data not shown).

Because the devel opmental N orthern blots of MEKK $\alpha$ mutants suggested an abnormality in cell-type differentiation that usually causes aberrant spatial patterning, we examined the spatial patterning of prestalk and prespore cells in the mek $\alpha^{-}$- and MEKK $\alpha$-overexpressing strains by using cell-type-specific lacZ reporters and histochemical staining for $\beta$-gal activity. In mekk $\alpha-$ slugs, there was a decrease in the size of the prespore zone (staining region; Fig. 3Ba,d) as shown by the expression pattern of the prespore reporters SP60/GFP and SP60/ lacZ (Haberstroh and Firtel 1990; data for SP60/GFP not shown). There was a concomitant increase in the size of the prestalk zone stained by ecmA O/lacZ reporter (Fig. $3 \mathrm{Bb}$, compare to wild-type Fig. 3Bd,e). [ecmAO is the promoter of the ecmA gene and is expressed at a high level in pstA cells and a lower level in pstO cells (Early et al. 1993).] This increase in the prestal $k$ region appears to be specific for the pstO cells, as observed by the size of the region expressing ecmO/lacZ, a reporter expressed in pstO cells and anterior-like cells (ALCs) (Early et al. 1993; Fig. 3B, cf. c and f). The size of the more anterior pstA domain, as determined by the expression pattern of the pstA-specific reporter ecmA/lacZ, was the same as in wild-type cells (data not shown). These data indicate that prespore cell-type differentiation is compromised in mek $\alpha^{-}$slugs and there is an increase in the size of the pstO domain.

In addition to an increase in the size of the region occupied by pstO cells, we observe that the pstO (ecmO / lacZ-expressing) cells are more scattered within the slug and do not form a tight domain as they do in wild-type slugs (Fig. 3BC). Comparison of the staining patterning in many slugs indicates that the pstO and prespore domains overlap partially (Fig. 3Ba,b), suggesting an intermixing of the pstO and prespore cells in this region. Thus, mekk $\alpha^{-}$slugs appear to lack the normally well-defined boundary between the prespore and prestalk domains. To determine if this potential overlap of the prestalk and prespore domains might be accounted for by cells that express both prestalk and prespore markers, double immunofluorescence staining was performed in mekk $\alpha^{-}$ cells expressing the ecmO/lacZ reporter using the MUD1 prespore cell-specific mAb (Krefft et al . 1985) and an antibody against $\beta$-gal to identify pstO cells. N o cells that expressed both markers were observed (data not shown).

A role for $M E K K \alpha$ in regulating cell-type patterning is even more evident from the staining pattern of the cell- 
Figure 3. Analysis of gene expression and patterning in MEKK $\alpha$ mutants. (A) Northern bl ot analysis of total RN A prepared from wild-type, mekk $\alpha^{-}$, and MEKK $\alpha^{\mathrm{K} 199 \mathrm{~A}}$ overexpressing cells at different stages of development as indicated. Blots were hybridized with probes for ecmA (prestalk-specific), SP60 (prespore-specific), SpiA (spore-specific), and ecmB (pstB- and ALC-specific). (B) Spatial patterning of prestalk and prespore cells in wild-type and mekk $\alpha^{-}$strains. Cells were transformed with the cell-type-specific lacZ reporter. For all lacZ expression studies, clonal isolates were used and several independent isolates were examined. Representative organisms are shown. Each panel is labeled to indicate the marker used and the genetic background. The arrowhead in a (SP60/lacZ, mekk $\alpha^{-}$cells) points to the lighter staining area in the region of potential pstO/prespore domain overlap. The arrowhead in b (ecmAO/lacZ, mekk $\alpha^{-}$cells) points to the extended prestalk-staining region in mek $\alpha^{-}$cell slugs. The arrowheads

in c (ecmO /lacZ, mekk $\alpha^{-}$cells) points to the larger pstO domain that shows a more scattered pattern (not all cells stain) and a region of potential pstO/prespore domain overlap. (C) Spatial patterning of prestalk and prespore cells in strains overexpressing M EKK $\alpha \Delta W D$. Cells expressing M EKK $\alpha \Delta$ WD show very scattered staining throughout most of the slug of the pstA-and pstO/ALC-specific reporters ecmA/lacZ and ecmo/lacZ, respectively.

type reporters in cells expressing MEKK $\alpha \Delta W D$. In these strains, prespore cells were present almost uniformly throughout most of the slug and found al most to the very anterior (Fig. 3Cc). However, the staining appeared very diffuse, suggesting that not all of the cells in this expanded region express the marker. Consistent with this observation, staining of the pstO- and pstA-specific reporters ecmO/lacZ and ecmA/lacZ, respectively, was also diffuse and scattered throughout most of the slug, with an apparent loss of the normally distinct pstA, pstO, and prespore compartments (Fig. 3Ca,b, compare to wild-type pattern, Fig. 3Bf,g). These data suggest that MEKK $\alpha$ levels, and presumably kinase activity, are important in regulating the position of pstO and prespore cells within the slug.

Spatial patterning of prestalk and prespore cells in chimeras: mek $\alpha^{-}$cells differentiate into prestalk cells preferentially

A decrease in the number of prespore cells and an increase in pstO cells in mekk $\alpha^{-}$cells suggest that, in the absence of MEKK $\alpha$ function, cells might have a tendency to differentiate into prestalk cells. To better understand the properties of the mek $\alpha^{-}$cells, we observed the developmental potential and the position of wild-type and MEKK $\alpha$ mutant strains tagged with GFP or lacZ reporter in chimeric organisms. This allows us to differentiate between potentially cell-autonomous and nonautonomous functions. When mekk $\alpha^{-}$cells expressing Act15/ GFP (which is uniformly expressed in all cells) were mixed with wild-type cells in a ratio of 1:3 and plated for development (Fig. 4Aa,b), most of the mekk $\alpha^{-}$cells in slugs were local ized to the anterior prestalk domain and the most posterior rearguard compartment. The rearguard compartment is composed of two prestalk cell types: ALCs and pstAB-derived cells (Sternfeld 1992). In the fruiting body, mek $\alpha^{-}$cells differentiate mainly into the lower portion of stalk and the basal disk (derived from rearguard cells) and upper cup of fruiting body (derived from pstO/ALCs). Few mekk $\alpha^{-}$cells were found in the prespore domain and mekk $\alpha^{-}$cells did not differentiate into spores, as no GFP-expressing spore cells were observed (Fig. 4AC; data not shown). The fruiting bodies exhibited an enlarged lower stalk and basal disc, suggesting that the chimeras contain an elevated number of pstO and A LCs, probably differentiated from the mek $\alpha^{-}$ cells. mekk $\alpha^{-}$prestalk cells (as defined by those expressing ecmAO/GFP) were localized in the tip of chimeric mound and the basal disk, lower portion of the stalk, and upper and lower cups of the sorus (Fig. 4Ba,b; the light staining on the sorus in Fig. 4Bb is caused by the ALCderived 'epithelial' layer often found covering the sorus). These results suggested that in chimeras with wild-type cells, mekk $\alpha^{-}$cells differentiated into prestal k cells preferentially.

To examine whether mekk $\alpha^{-}$cells have a cell-autonomous defect that prevents them from differentiating into prespore cells in these chimeras, mekk $\alpha^{-}$cells were tagged with the prespore-specific reporter SP60/GFP. In the tipped aggregate, when cell sorting first establishes the spatial pattern of the cell types, SP60-GFP-tagged mek $\alpha^{-}$cells were found primarily in a band below the prestalk domain in the very anterior of the prespore re 
A WT: $m e k k \alpha$ null-Act/GFP (3:1)

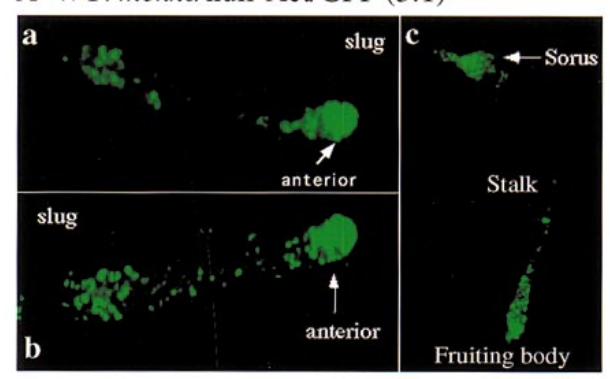

B WT: $m e k k \alpha$ null-GFP $(3: 1)$

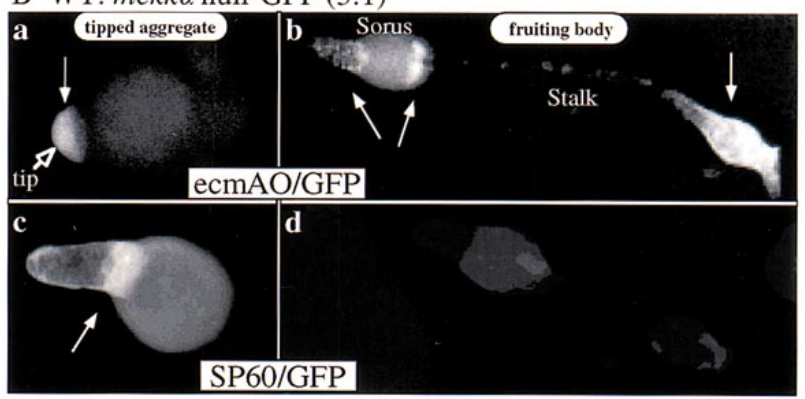

C WT (lacZ): mekk $\alpha$ null or MEKK $\alpha$ OE (1:3)

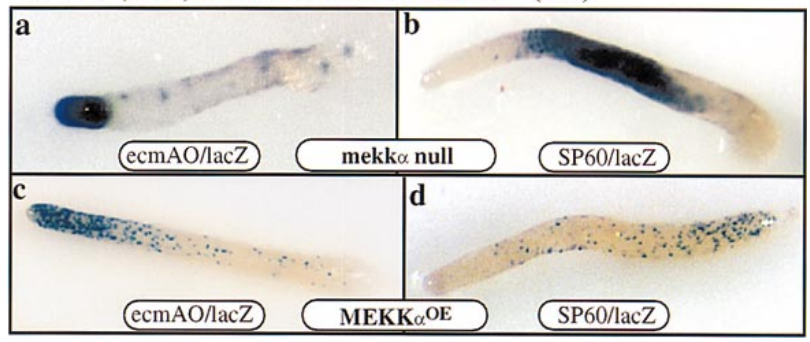

Figure 4. Spatial patterning in chimeric slugs. (A) Prestalk localization of mek $\alpha^{-}$cells expressing Act15/GFP in the chimera of wild-type cells and mekk $\alpha^{-}$cells in a ratio of 3:1. (B) Localization of null cells expressing ecmA/GFP or SP60/GFP in chimeras of wild-type and null cells in a ratio of 3:1. Null cells expressing ecmA / GFP localize in the tip of the mound and later develop into stalk cells. Null cells expressing SP60/GFP are concentrated in the region near the tip of mounds. However, the expression of SP60/GFP is not prominent in the mature fruiting body. Arrowheads indicate cells expressing GFP. (C) Localization of wild-type cells in chimeras of null and wild-type cells (3:1) or MEKK $\alpha$ overexpression mutants and wild-type cells (3: 1). (c and d) Chimeras containing one part wild-type cells and three parts $\mathrm{MEKK} \alpha^{\mathrm{OE}}$ cells. Patterns of wild-type cells expressing either ecmAO/lacZ (c) or SP60/lacZ (d) are shown.

gion (Fig. 4Bb). However, expression of this marker was lost subsequently and, by mid-culmination (Fig. 4Bd) or later stages (data not shown), no GFP was detected. The simplest explanation is that mekk $\alpha^{-}$prespore cells form in these chimeras initially and then the expression of this marker is lost in mekk $\alpha^{-}$cells, probably because differentiation of the putative mekk $\alpha^{-}$prespore cells is not stable. This is consistent with the mekk $\alpha^{-}$cells in chimeras contributing only to the prestalk and stalk compartments in slugs and fruiting bodies. Reciprocal mixing experiments in which one part tagged wild-type cells was mixed with three parts unlabeled mekk $\alpha^{-}$cells support the above model. Wild-type cells were able to form the very anterior of the prestalk domain as shown by the fact that ecmAO/lacZ-tagged wild-type cells localized to the very anterior pstA domain, as do mekk $\alpha^{-}$ cells (Fig. 4Ca). The wild-type prespore cells localize to a central band of cells in the slug (Fig. $4 \mathrm{Cb}$ ). A large posterior domain, seen as an unstained region in the SP60/ lacZ panel, must be composed of mekk $\alpha^{-}$cells and presumably represents an enlarged rearguard domain (see above), which is probably composed of mostly mekk $\alpha^{-}$derived pstO/ALCs. In toto, these data are consistent with the decreased ability of mek $\alpha^{-}$cells to participate in the formation of the prespore domain in the slug in the presence of wild-type cells. As mekk $\alpha^{-}$cells form a true prespore domain when devel oped by themsel ves, we suggest that this regulation is nonautonomous and dependent on morphogenetic factors such as CAM P and the prestalk differentiation factor DIF in the slug and the ability of mekk $\alpha^{-}$and wild-type cells to sense and respond to these factors.

Because mekk $\alpha^{-}$cells have a propensity to become prestalk cells, it is reasonable to bel ieve that cells having higher activity of $\mathrm{MEKK} \alpha$ differentiate into prespore cells. Thus, similar chimeric analyses were conducted with Act15/MEKK $\alpha^{\mathrm{OE}}$ wild-type cells mixed with wildtype cells carrying lacZ reporters in a ratio of 3:1 (Fig. $4 \mathrm{C} c$,d). In contrast to the above chimeric analysis, wildtype cells local ized preferentially to the prestalk rather than the prespore region of migrating slugs (Fig. $4 C \mathrm{C}, \mathrm{d}$ ). Wild-type cel Is expressing the prestal $\mathrm{k}$ reporter ecmA O / lacZ showed staining that extended over the pstA and pstO domains, indicating that the wild-type cells differentiated into pstA and pstO cells in the chimeras. However, very few wild-type prespore cells formed, as indicated by the few wild-type cells within the slug that express the prespore reporter SP60/lacZ. These were found concentrated towards the posterior of the prespore domain. Thus, in mekk $\alpha /$ wild-type chimeras, mekk $\alpha^{-}$ cells become prestal $k$ cells preferentially and do not contribute to the prespore domain, whereas in $\mathrm{MEKK} \alpha \mathrm{OE}$ / wild-type chimeras, very few of the wild-type cells contribute to the prespore domain. These data suggest that the level of expression of MEKK $\alpha$ determines the propensity to contribute to the formation of the prestal $\mathrm{k}$ or prespore domains in a chimera.

\section{Subcellular localization of MEKK $\alpha$}

The fact that we obtained dominant phenotypes by overexpressing the F-box and WD 40 repeats suggests that the F-box/WD 40 domain of MEKK $\alpha$ might interact with proteins that play important roles in regulating the activity and subcellular localization of MEKK $\alpha$. We examined the subcellular localization of the F-box/WD40 and MEKK $\alpha$ by using GFP-F-box/WD40 fusion protein or FLAG-tagged MEKK $\alpha$. The F-box/WD 40-GFP fusion protein exhibited a predominantly cortical staining (Fig. $5 A$ ), suggesting that these domains might localize MEKK $\alpha$ to the membrane. Controls with GFP alone 

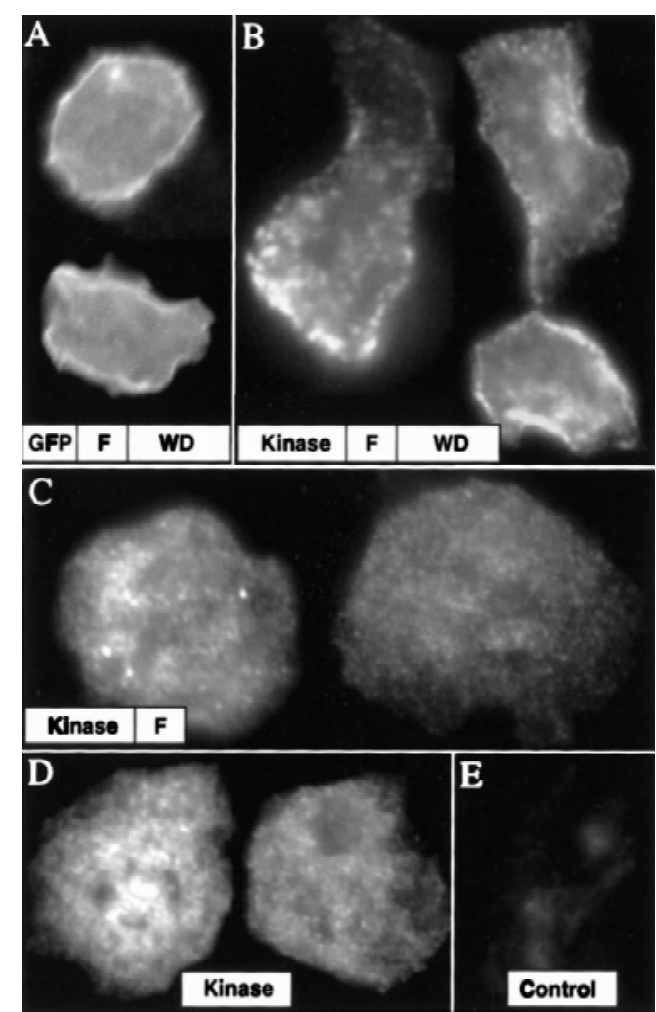

Figure 5. Subcellular localization of MEKK $\alpha$. (A) Localization of GFP-tagged F-box/WD40 protein in the cortical region of the cytoplasmic membrane. (B) Immunofluorescence staining of cells expressing Flag-tagged MEKK $\alpha$. The staining is clustered and mainly localized in the membrane cortex. (C) Staining of a truncated Flag-M EKK $\alpha$ from which WD40 repeats were deleted (MEKK $\alpha \Delta$ WD 40). (D) Staining of FLAG-MEKK $\alpha$ missing both F-box and WD40 repeats (MEKK $\alpha \Delta F$-box/WD40). (E) Control, untransformed cells.

showed a uniform staining pattern throughout the cell (data not shown). Consistent with the distribution of GFP-F-box/WD40, MEKK $\alpha$ was localized predominantly at the periphery of the cells, possibly in the cortex or the plasma membrane as exami ned by indirect immunofluorescence staining (Fig. 5B). However, FLAG$M E K K \alpha$ staining was not distributed uniformly but showed a clustered, granular pattern. FLAG-tagged MEKK $\alpha$ lacking WD40 repeats (Fig. 5C) or both the F-box and WD40 repeats (containing only the kinase domain; Fig. 5D) were no longer targeted to the membrane, but found in clusters throughout the cytoplasm, supporting the model that the WD 40 repeats are an important component in targeting MEKK $\alpha$ to the cell cortex or plasma membrane.

The F-box/WD 40 repeat domain interacts with components of the ubiquitination/ deubiquitination pathway and regulates MEKK $\alpha$ stability

We performed two-hybrid screens to identify Dictyostelium proteins that might interact with the MEKK $\alpha$ F- box and WD 40 repeats (Lee et al. 1997). One of the genes recovered in the screen is $\mathrm{UbcB}$, encoding an E2 class ubiquitin-conjugating enzyme that links ubiquitin covalently (often in association with E3 ligase) to proteins to be degraded by 265 proteasomes (Varshavsky 1997). We isolated this gene previously in a REM I screen and ubcB null ( $(\mathrm{bbcB} \rightarrow$ ) cells show a delay at the mound stage and eventually arrest at the first finger stage (Clark et al. 1997). A nalysis of these cells showed that the developmental pattern of several ubiquitin-linked proteins was altered. A nother identified gene encodes a putative UBP (designated UBPB), a potential ubiquitin hydrolase that removes ubiquitin from proteins. These enzymes are thought to play roles in stabilizing proteins by preventing them from being targeted for degradation and/or in ubiquitin precursor processing (Hochstrasser 1995, 1996). The sequence of the U bpB open reading frame (ORF) reveal ed the conserved Cys and His sequence motifs, which may form an active site and are conserved in all known UBPs (not shown).

$\mathrm{U}$ bpB expresses a single developmentally regulated transcript $(2.0 \mathrm{~kb})$ that is found at low levels in vegetative cells and at higher levels during aggregation and mound formation ( 4 and $8 \mathrm{hr}$; Fig. 6A). U bpB was disrupted by homologous recombination and disruptants were identified by Southern blot analysis as described for mekk $\alpha^{-}$cells (see Materials and M ethods). As observed with mekk $\alpha^{-}$cells, ubpB null (ubpB ${ }^{-}$) cells exhibit precocious development, similar to that of mekk $\alpha^{-}$strains. They form fruiting bodies at $\sim 17 \mathrm{hr}$ (Fig. 6C; data not shown) and exhibit precocious expression of the spore marker SpiA (Fig. 6B). The expression levels of the prespore/ spore markers are lower in the ubpB ${ }^{-}$cells compared to wild-type cells, whereas expression of the prestalk/stalk marker ecmB is el evated slightly.

We performed an analysis of cell-type patterning in $\mathrm{ubpB}^{-}$cells similar to that described above for mekk $\alpha^{-}$ cells using cell-type-specific reporters. Our analyses of $\mathrm{ubpB}^{-}$cells show an enlarged prestalk domain (ecmAO / IacZ) and a reduced prespore (sp60/lacZ) domain in the slug and spore domain in a fruiting body (Fig. 6C). Moreover, the strain does not form the normal spherical sori seen in mature wild-type fruiting bodies. Instead, the sori remain el ongated, similar to those seen in wild-type fruiting bodies that are not fully mature (Fig. 6C). The upper and lower cups of the fruiting body, which are derived from prestalk cells and ALCs, are enlarged. The spore-containing region, as determined from SpiA/lacZ expression, is reduced. These abnormal ities suggest that UBPB activity is required for proper prespore cell patterning and $\mathrm{ubpB}^{-}$cells differentiate into prestalk cells preferentially.

To determine if $\mathrm{ubpB}^{-}$cells al so have a propensity to become prestalk cells, we examined the fate of ubpB ${ }^{-}$ cells in similar mixing experiments. ubpB ${ }^{-}$cells were tagged with Act15/GFP and mixed with wild-type cells in a ratio of 1:3. As with mek $\alpha^{-}$cells, most of the tagged $\mathrm{ubpB}^{-}$cells localized to prestalk-derived compartments in the anterior and posterior of the slug and differentiated into the lower stalk and basal disk in mature fruit- 
A

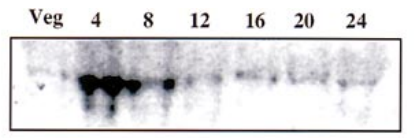

B
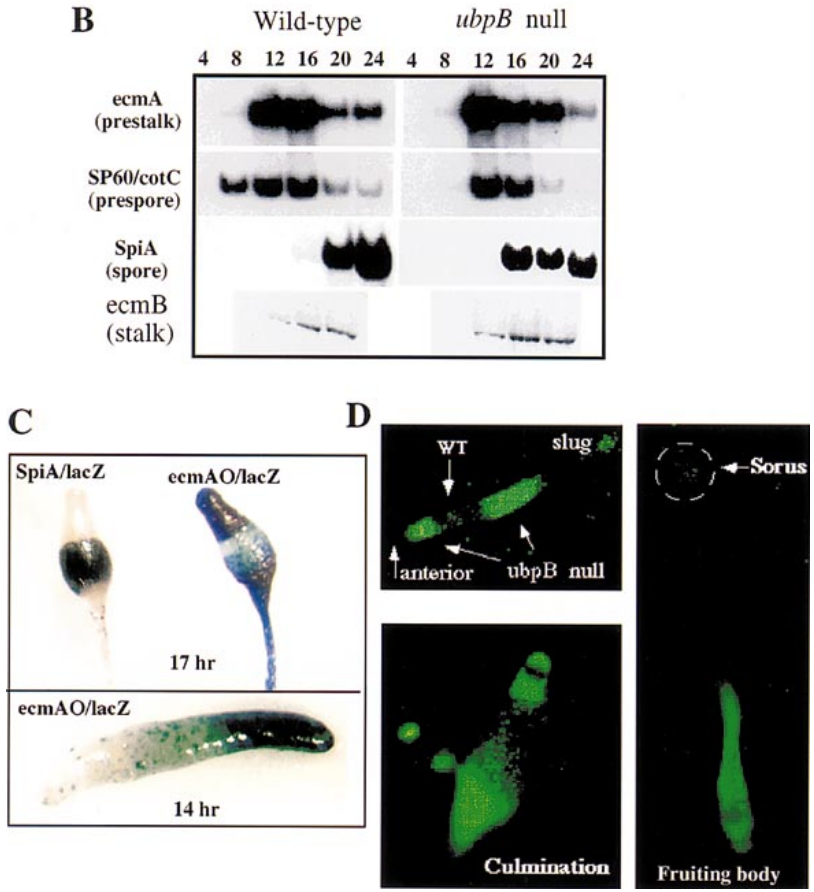

Figure 6. Analysis of UBPB expression during growth and de velopment and the phenotype of the $\mathrm{ubpB}^{-}$mutant. (A) Developmental RNA blot of UBPB expression. Time in development is shown. (Veg) Vegetative cells. (B) N orthern blot analysis of total RN A prepared from wild-type and $\mathrm{ubpB}^{-}$cells at different stages of development. Blots were hybridized with probes for ecmA, SP60, ecmB, and SpiA. (C) Spatial patterning of prestalk and prespore cells in $\mathrm{ubpB}^{-}$strains. Cells were transformed with the prespore-specific reporter $\mathrm{SP60} / \mathrm{IacZ}$, ecmAO/lacZ, or Spi A/lacZ and clones were isolated. In ubpB ${ }^{-}$cells, the prespore region containing cells expressing SP60/lacZ is reduced compared to the wild-type prespore region. The pstA/O domain is expanded in null cells. (D) Prestalk localization of $\mathrm{ubpB}^{-}$cells expressing Act15/GFP in the chimera of wild-type cells and ubpB $^{-}$cells in a ratio of 3:1.

ing bodies (Fig. 6D). This suggests that $\mathrm{ubpB}^{-}$cells, like mek $\alpha^{-}$cells, have a propensity to develop into prestalk cells.

Differential stability of MEKK $\alpha$ in various genetic backgrounds: evidence for regulation of $\mathrm{MEKK} \alpha$ stability by U BCB and U BPB

Identification of UBC and UBP as MEKK $\alpha$-interacting proteins suggests that MEKK $\alpha$ may be regulated by ubiquitin-dependent degradation. This possibility is consistent with the fact that MEKK $\alpha$ has an F-box sequence that is thought to be involved in ubiquitin-dependent degradati on of cycl in F and other proteins (Bai et al. 1996; Skowyra et al. 1997). To examine whether MEKK $\alpha$ has a differential stability in $\mathrm{ubcB}^{-}$and $\mathrm{ubpB}^{-}$cells and whether that stability is mediated via the F-box/WD 40 repeats, a myc-tagged F-box/WD40 domain was expressed from the Act15 promoter in wild-type, ubcB ${ }^{-}$, and $\mathrm{ubpB}^{-}$cells (Fig. 7A). In wild-type cells, the level of the tagged protein (as marked by the closed arrowhead) was high during early development, but decreased in amount during later development after mound formation. No bands were observed in control, untransformed cells, indicating that the observed bands were specific for those carrying the myc epitope. In addition, a higher molecular weight band (open arrowhead), which probably is polyubiquitinated, was observed that al so decreased after mound formation. Bands of this same mobility react with an anti-ubiquitin antibody (see below, Fig. 7B). Lower molecular weight myc-tag-containing bands, which may represent degradation products as they carry the myc tag, were observed. In ubcB- cells, a band the size of the tagged F-box/WD 40 repeats accumulated in intensity during development and a reduced amount of the higher molecular weight band was seen. The latter observation would be predicted if UBCB participated in the ubiquitination of MEKK $\alpha$ via the F-box/WD40 repeats, which then targeted the protein for degradation. In ubpB $^{-}$cells, the tagged F-box/WD 40 band and a diffuse higher molecular weight set of bands were observed in vegetative cells. As development proceeded, the intensity of the band of the F-box/WD40 repeats decreased significantly faster than the band of wild-type cells.

We examined the ubiquitination of F-box/WD40 repeats during development by performing immunoprecipitation of the myc-tagged F-box/WD40 protein with anti-myc antibody followed by probing a Western blot with anti-ubiquitin antibody (Fig. 7B). In wild-type cells, we observed higher molecular weight polyubiquitinated bands (open arrowhead), with the level of ubiquitination peaking at 4-8 hr of development. Starting at the mound stage (8 hr of development), smaller bands were observed. We observed these smaller bands also in the Western blot of FLAG-tagged holo-MEKK $\alpha$, so these bands are likely to represent the degradation products of F-box/WD 40. They are not observed in control, untransformed cells (data not shown). Similar to our observations in wild-type cells, a strong, polyubiquitinated Fbox/WD 40 band was detected at $8 \mathrm{hr}$ of development in $\mathrm{ubpB}^{-}$cells, as were many lower molecular weight bands. This finding suggests the F-box/WD 40 protein is ubiquitinated and degraded extensively at this time in development. In ubcB ${ }^{-}$cells, we observed a significantly reduced level of ubiquitinated F-box/WD40 and the smaller molecular weight degradation products. However, there was still a signal at the position of the F-box/ WD40 repeat in the gel, suggesting that some ubiquitination occurred and there is some redundancy in the ubiquitination pathway. These results are consistent with the F-box/WD40 repeat protein being polyubiquitinated and requiring UBCB for efficient ubiquitination and the targeting of the protein for degradation. Our results are also consistent with UBPB stabilizing the Fbox/WD40 repeat protein by deubiquitinating the protein. 
Figure 7. Ubiquitin-mediated degradation of MEKK $\alpha$. (A) Western blot analysis of the stability of myc-tagged F-box/WD40 protein in wild-type, $\mathrm{ubpB}^{-}$, and $\mathrm{ubcB}^{-}$cells. Extracted proteins $(20 \mu \mathrm{g})$ were resolved in a $10 \%$ polyacrylamide gel, blotted onto PVDF membrane, and stained with antimyc antibody. Closed arrowheads indicate the position of the expected 60-kD F-box/ WD40 protein and open arrowheads indicate the higher molecular weight proteins, which might be polyubiquitinated. (B) Western blot analysis of immunoprecipitated F-box/WD40 protein with anti-ubiquitin antibody. myc-F-box/WD40 protein in wild-type, $\mathrm{ubpB}^{-}$, and $\mathrm{ubcB}^{-}$cells was immunoprecipitated with anti-myc antibody and probed with anti-ubiquitin antibody. Solid arrowheads indicate the F-box/ WD40 protein and open arrowheads indicate polyubiquitinated proteins. (C) Western blot analysis of the stability of Flag-tagged MEKK $\alpha$ in different genetic backgrounds. Solid arrowheads indicate the expected 100-kD MEKK $\alpha$ and open arrowheads indicate smaller protein bands that might be proteolitic degradation productions. (D) Differential stability of the GFP-F-box/WD40 fusion in living wildtype and $\mathrm{ubpB}^{-}$slugs. GFP (a) or GFPtagged F-box/WD40 fusion protein was ex
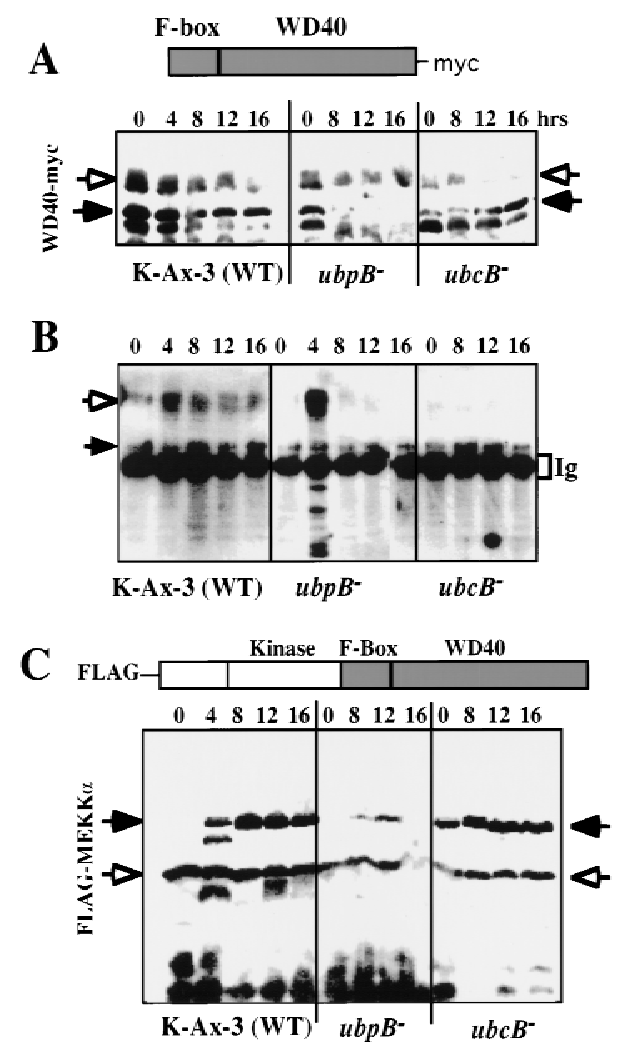

D
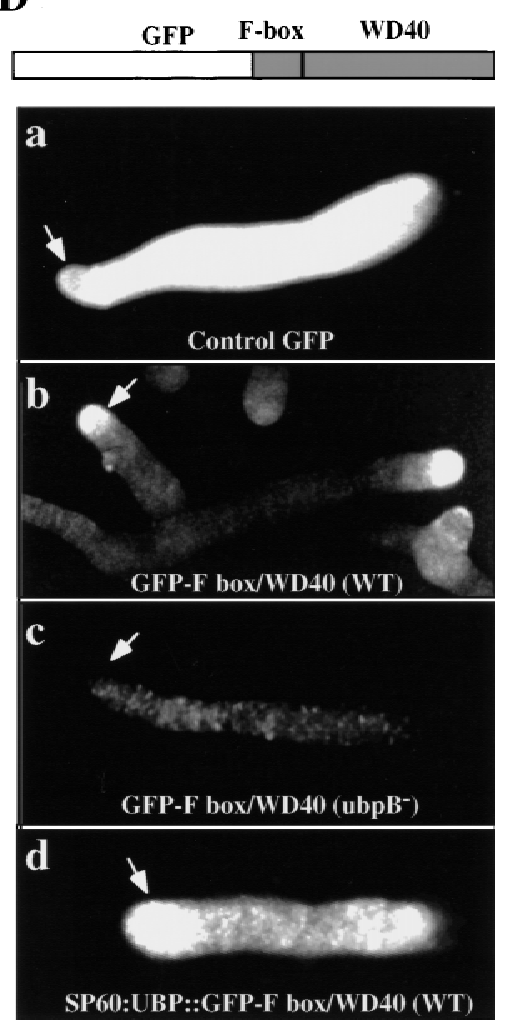

pressed in wild-type (b) and $\mathrm{ubpB}^{-}$(c) cells.The higher GFP fluorescence in the pstA domain suggests that the turnover of the GFP-F-box/WD40 might be regulated spatially. (d) Wild-type cells expressing constitutively GFP-tagged F-box/WD 40 from the Act15 promoter and UBPB from the SP60 promoter, which directs expression in prespore cells. The samples shown in A and B are from different experiments. Control blots of untransformed wild-type cells show no immunoprecipitated bands using the anti-myc antibody.

We also examined the stability of a Flag-tagged holo$\mathrm{MEKK} \alpha$ in the three genetic backgrounds. As shown in Figure 7C, no detectable full-length MEKK $\alpha$ is found in vegetative wild-type cells, although we observe an 55kD protein, which may be either a cleavage or degradation product (see below). In addition, we observe a large amount of material migrating as very low molecular weight bands, which we expect are degradation products. Full-length MEKK $\alpha$ protein was observed by $4 \mathrm{hr}$ of development, the time when UBPB expression increases. The amount of this band stays constant during development. In ubcB ${ }^{-}$cells, the tagged M EKK $\alpha$ is stable and the presence of the $\sim 55-k D$ band is observed. An important observation is that very few of the smaller bands, presumably $\mathrm{MEKK} \alpha$ degradation products, are observed, suggesting that $\mathrm{MEKK} \alpha$ degradation is reduced in this strain. In contrast, the tagged MEKK $\alpha$ is very unstable in $\mathrm{ubpB}^{-}$cells and only a small amount of the full-length protein or the $\sim 55-\mathrm{kD}$ band is observed at any stage of development. Instead, we observed numerous lower molecular weight bands that presumably represent degradation products. By comparing the amount of the fulllength $\mathrm{MEKK} \alpha$ to the amount of low molecular weight, putative degradation products, we concl ude that $M E K K \alpha$ is least stable in ubpB $^{-}$cells and most stable in ubcB $^{-}$ cells. Interestingly, the 110-kD band representing FLA G- tagged MEKK $\alpha$ was absent in vegetative wild-type and ubpB $^{-}$cells. However, we observea FLA G-tagged protein of $\sim 55 \mathrm{kD}$, the expected size of MEKK $\alpha$ lacking the F-box and WD 40 repeats. As this protein is tagged at the amino terminus, the deleted protein must be lacking carboxyterminal residues including the WD 40 repeats. It is not clear if this is a normal cl eavage product or a result of the overexpression of $\mathrm{MEKK} \alpha$.

We also tested the ubiquitination of MEKK $\alpha$ in the three genetic backgrounds and found a pattern similar to that observed with the F-box/WD40 domain. MEKK $\alpha$ exhibited a lower level of ubiquitination in $\mathrm{ubcB}^{-}$cells than in wild-type cells, with the level higher in ubpB $^{-}$ cells (data not shown). The above data imply that $\mathrm{MEKK} \alpha$ exhibits differential stability in the three ge netic backgrounds, suggesting that MEKK $\alpha$ is degraded in a developmentally regulated fashion and UBCB and UBPB play a role in controlling MEKK $\alpha$ stability.

The speculation that the degradation of MEKK $\alpha$ might be cell-type specific arose from the observation of phe notypes from expressing MEKK $\alpha$ in prespore cells, but not in prestalk cells. To determine if we could observe a differential stability of the F-box/WD40 repeats in living wild-type and ubpB ${ }^{-}$slugs, we expressed GFP or GFP-Fbox/WD40 from the Act15 promoter. Clones that expressed similar level s of the transcript in vegetative cells 
were developed to the slug stage and examined for GFP fluorescence (Fig. 7D). [ $\mathrm{N}$ ote: $\mathrm{ubcB}^{-}$cells produce very few slugs, which are abnormal and not observed until 20 hr of devel opment (Clark et al. 1997).] In wild-type slugs expressing GFP-F-box/WD40, we observed a very high level of fluorescence in the anterior pstA domain but a much lower level of expression in the pstO and prespore domains (Fig. 7Db). This is in sharp contrast to control cells expressing free GFP, which showed very strong fluorescence that was distributed throughout the slug uniformly (Fig. 7Da, al so examined using shorter exposures; data not shown). Thus, the lower fluorescence of GFP-F-box/WD40 in the prespore domain suggests that GFP-F-box/WD40 turnover is spatially regulated, being higher in prespore than prestalk cells. ubpB ${ }^{-}$cells expressing GFP-F-box/WD40 showed an even lower level of fluorescence throughout the slug, suggesting that the GFP-F-box/WD40 fusion protein turned over rapidly in all cell types in this genetic background. These results are consistent with the F-box/WD40 repeats mediating turnover of the associated protein and UBPB differentially regulating stability of this protein in vivo. To test this further, we overexpressed UBPB only in prespore cells using the SP60 promoter in wild-type cells expressing GFP-F-box/WD40. As shown in Figure 7Dd, we observed high fluorescence in the prespore domain, especially in the posterior of this domain. This result indicates that overexpression of UBPB in prespore cells can help stabilize the GFP-F-box/WD40 protein in wild-type cells.

\section{Discussion}

MEKK $\alpha$ is required for pstO/prespore cell patterning and maintaining the prespore state of differentiation

We have identified a gene, $\mathrm{MEKK} \alpha$, which probably encodes a MEK kinase because of its very high homology in the kinase domain to known MEKKs, the first kinase in MAP kinase cascades. Our findings indicate that MEKK $\alpha$ plays a key role in a new regulatory pathway by which cell-type differentiation, morphogenesis, spatial patterning, and developmental timing are controlled. Whereas components of three MAP kinase pathways required for chemotaxis, activation of adenylyl cyclase, and prespore cell differentiation have been identified previously in Dictyostel ium (Gaskins et al . 1994, 1996; Segall et al . 1995; Ma et al. 1997), we expect that they are independent pathways and unrel ated to the pathway containing MEKK $\alpha$. MEKK $\alpha$ contains an F-box, a domain known to control ubiquitinmediated degradation of proteins, and WD40 repeats, which we show are important for targeting MEKK $\alpha$ to the cell cortex or possibly the plasma membrane. We demonstrate that MEKK $\alpha$ 's stability, and thus its function, is differentially regulated temporally and in a cell-type-specific fashion via developmentally regulated ubiquitination/deubiquitination. Our results represent a novel mechanism by which MAP kinase cascade components can be controlled.

Our data suggest that MEKK $\alpha$ plays several roles in regulating cell-type patterning and morphogenesis. We have shown that disruption of MEKK $\alpha$ or overexpression of a putative dominant negative construct (M EKK $\alpha^{\mathrm{K} 199 \mathrm{~A}}$ ) results in a loss of proper spatial patterning, including an expansion of the pstO domain, a concomitant reduction of the prespore domain, a smaller sorus, and a longer stalk. This indicates that $\mathrm{MEKK} \alpha$ may be required to maintain the proportions of prespore cells in the multicellular organism. MEKK $\alpha$ also controls the boundaries between these two distinct cell-type compartments within the organism. In the null and overexpression strains, the tight cell-compartment boundaries are lost and there is an intermixing of the cell types. The effect is very extreme in strains overexpressing MEKK $\alpha \Delta W D$ in which pstA, pstO, and prespore cells are mixed throughout the slug. The phenotype could result from cells losing their spatial identity within the slug because of an abrogation of the patterning signals, thought to be CAMP and DIF, which control a cell's position within the organism and its fate (Kay 1992; Loomis 1993; Ginsburg et al. 1995; Siegert and Weijer 1995; Williams 1995; Firtel 1996; Bretschnei der et al. 1997). Alternatively, cells may lose the ability to sense and/ or respond to these si gnals, which causes the alteration in their ability to sort in the multicellular aggregate, leading to a loss of compartment boundaries and, in the most extreme examples, an intermixing of the cell types.

The other phenotype is that mekk $\alpha^{-}$cells develop more rapi dly than wild-type cells, with the major change in timing occurring after the mound is formed, the time when M EKK $\alpha$ expression increases during development. M ore rapid development is an earmark of strains having constitutively active PKA, which is known to be essential for prespore differentiation, culmination, and spore formation (A be and Yanagi sawa 1983; Simon et al . 1992; Firtel 1995; Reymond et al. 1995; Mann et al. 1997). $M E K K \alpha$ may integrate into this pathway. In all cells, overexpression of MEKK $\alpha$ or MEKK $\alpha \Delta$ WD 40 results in very delayed development in which many of the aggregates arrest at the mound stage. The effect appears to result from expression in prespore cells, as overexpression of MEKK $\alpha$ from the SP60 prespore promoter but not the ecmAO prestalk promoter produces a similar delay and additional aberrant morphological phenotypes. The results suggest that $\mathrm{MEKK} \alpha$ function is required at the time of cell-type differentiation and patterning for establishment and maintenance of proper proportioning and patterning. Its degradation, possibly preferentially in prespore cells, appears to be required for proper onset of later development and morphogenesis.

We also observed that mekk $\alpha^{-}$and $\mathrm{ubpB}^{-}$cells differentiate preferential ly into structures that derive from the prestalk cell populations in a chimeric organism. This is consistent with the increase in the size of the pstO compartment in mekk $\alpha^{-}$and $\mathrm{ubpB}^{-}$slugs. Moreover, it further supports the suggestion that mekk $\alpha^{-}$cells have a reduced ability to form and/or maintain prespore cell fate, leading to an impairment in proper prestalk:prespore proportioning, possibly because of a reduced ability to recognize the morphogenetic cues within the organism. In Dictyostelium, development is highly regulative 
and a cell's fate is not finally determined until culmination. Before that, prestalk and prespore cells can interconvert via a pathway that has been termed transdifferentiation, which is thought to play a role in the maintenance of spatial patterning in the slug (A be et al. 1994). The uncommitted fate of cells in Dictyostelium slugs indicates that the cells are able to respond to environmental cues continually to regulate their state of differentiation and thus control the patterning of the organism. Our data suggest that MEKK $\alpha$ is one of the critical components controlling the equilibrium between the cell types, probably by maintaining prespore differentiation. We show that although mekk $\alpha^{-}$prespore cells are formed in chimeras with wild-type cells, as determined by SP60/GFP expression, GFP expression is lost in the chimeras (Fig. 4B). The simplest explanation is that SP60-expressing mekk $\alpha^{-}$cells must dedifferentiate and then differentiate into prestalk cells and eventual ly stalk cells later in devel opment. This conclusion is consistent with our observation that mekk $\alpha^{-}$cells appear to participate exclusively in prestalk-derived structures in the chimeric fruiting body. It is thus possible that not only is prespore cell differentiation of mekk $\alpha^{-}$cells unstable in chimeras with wild-type cells, but prespore differentiation is compromised generally in this genetic background. Conversely, we show that in chimeras of wildtype and $\mathrm{MEKK} \alpha{ }^{\mathrm{OE}}$ cells, the wild-type cells preferentially become prestalk cells and the MEKK $\alpha{ }^{\mathrm{OE}}$ cells become prespore cells. This further supports the conclusion that the level of MEKK $\alpha$ expression helps determine whether a cell differentiates into a prestalk or prespore cell. As this is occurring in chimeras, it must do this in the context of the signals within the slug. It is unclear whether the complete loss of the compartment boundaries in $\mathrm{MEKK} \alpha{ }^{\mathrm{OE}}$ cells and the intermixing of the cell types is the result of continuous transdifferentiation of pstO to prespore cells and vice versa in the region adjoining the pstO and prespore compartments.

Interactions among various activation pathways and lateral inhibitions are thought to be involved in regulating prestalk and prespore differentiation (Kay 1992; Loomis 1993; Williams 1995; Firtel 1996). Thereare several known genes that function to control spatial patterning of prespore and prestalk cells and might function in the pathway mediated by MEKK $\alpha$. Strains carrying null mutations of the CAM P receptor CAR4, which is thought to negatively regulate GSK3 and antagonize pathways controlled by CAR1 and 3 (Ginsburg and Kimmel 1997), or the RIN G-leucine zipper protein rZIP (Bal int-Kurti et al. 1997), have a reduction in prestalk cells and increased prespore cells and, like strains exhibiting altered MEKK $\alpha$ function, a loss of the sharp pstO/prespore compartment boundary. Our data are consistent with $\mathrm{MEKK} \alpha$ acting to antagonize pathways mediated by CAR4 and rZIP and activated by CAR1/3.

MEKK $\alpha$ levels are spatially regulated through protein ubiquitination/deubiquitination pathways

Protein ubiquitination followed by the 265 proteasomedependent proteolysis is crucial to a variety of cellular processes (Ciechanover 1994; Hochstrasser 1995, 1996). The ubiquitination is composed of multiple reactions requiring a series of specific enzymes, including ubiquitin-conjugating enzymes (UBC or E2). The predicted sequence of MEKK $\alpha$ has an F-box sequence and WD40 repeats, which are often found in proteins subjected to degradation via a ubiquitin-dependent pathway (Bai et al. 1996). Several proteins involved in cell-cycle regulation such as Cdc4 and Met30 of budding yeast, MD6 of mouse, and Cyclin F and Skp2 of human have an F-box, which is sometimes associated with WD40 repeats (Cdc4, M et30, M D6). The F-box has been suggested to be a receptor for phosphorylated ubiquitination targets, with Skpl linking the F-box/target complex to ubiquitination machinery (Bai et al. 1996; Skowyra et al. 1997). Our data are consistent with the conclusion that the F-box/WD40 repeats in $\mathrm{MEKK} \alpha$ control MEKK $\alpha$ turnover via ubiquitination and deubiquitination. A UBC and a UBP were identified as proteins interacting with MEKK $\alpha$ in a yeast twohybrid screen. mekk $\alpha^{-}$and $\mathrm{ubpB}^{-}$cells develop rapidly, show increased prestalk and decreased prespore domains, and differentiate preferential ly into prestalk cells in chimeras with wild-type cells. UBPs are thought to remove ubiquitin from proteins, making them less likely to bedegraded by the $26 \mathrm{~S}$ proteasome. The loss of UBP function, therefore, might lead to increased MEKK $\alpha$ ubiquitination and a more rapid turnover of $\mathrm{MEKK} \alpha$, as our data suggest. This should result in a reduced level of MEKK $\alpha$ activity, possibly producing a phenotype similar to that of mekk $\alpha^{-}$cells, as we observe.

Cells lacking the E2 UBCB (ubcB- cells), like $\mathrm{MEKK} \alpha{ }^{\mathrm{OE}}$ cells, exhibit a significant delay at the mound stage and arrest at the first finger stage (Clark et al . 1997). The developmental delay in $\mathrm{ubcB}^{-}$cells, in which $M E K K \alpha$ is more stable and thus might be expected to have higher MEKK $\alpha$ activity or be mislocalized, exhibits some properties similar to those of $\mathrm{MEKK} \alpha{ }^{\mathrm{OE}}$ strains. We have shown previously that multiple ubiquitinated proteins have altered developmental patterns of ubiquitination as determined on developmental Western blots using an anti-ubiquitin antibody (Clark et al. 1997). It is probable that the $\mathrm{ubcB}^{-}$phenotype results from altering the ubiquitination pattern and possibly the kinetics of degradation of several of these proteins.

The strongest evi dence for a role of UBPB and UBCB in the regulation of $M E K K \alpha$ turnover is the differential stability of the tagged F-box/WD40 protein and MEKK $\alpha$ in wild-type, $\mathrm{ubpB}^{-}$, and $\mathrm{ubcB}^{-}$cells. These proteins are most stable in $\mathrm{ubcB}^{-}$cells and least stable in $\mathrm{ubpB}^{-}$cells, consistent with UBCB controlling the ubiquitination and degradation of $\mathrm{MEKK} \alpha$ through the F-box/WD40 repeats and with UBPB regulating MEKK $\alpha$ 's stability. We show that the proteins are differentially ubiquitinated in the various genetic backgrounds. All of our data are consistent with our proposal that UBCB and UBPB regulate $M E K K \alpha$ stability. The data are also consistent with this regulation being developmentally controlled, as fulllength M EKK $\alpha$ expressed from the Act15 promoter is not detected in wild-type cel Is until the time of development when UBPB expression is induced. 
The observation that overexpression of mutant $\mathrm{MEKK} \alpha$ proteins results in phenotypes when the proteins are expressed in prespore but not prestalk cells al so suggests strongly spatial / cell-type regulation of MEKK $\alpha$ degradation. Our in vivo analysis examining the level and spatial distribution of GFP-F-Box/WD40 fluorescence in living slugs supports strongly the differential degradation of MEKK $\alpha$. In wild-type slugs, the GFP-FBox/WD40 showed a much stronger fluorescence in the anterior, pstA population than the remainder of the slug, compared to control GFP al one showing very strong fluorescence throughout the slug. In $\mathrm{ubpB}^{-}$cells, only a low level of scattered staining is observed, consistent with a higher rate of degradation of the protein in these cells. Thus, the Western bl ot data and the in vivo fluorescence analysis suggest strongly that the F-box and WD40 repeats target $M E K K \alpha$ for degradation and/or processing and this targeting may be spatially and temporally regulated in Dictyostelium. A strong indication that the stability is mediated by UBPB is derived from our results demonstrating that overexpression of UBPB in prespore cells stabilizes the GFP-F-Box/WD40 in these cells. We conclude that MEKK $\alpha$ is a substrate for UBCB and UBPB. Although substrates for other UBCs have been identified, we know of no reports in which a substrate for a UBP has been identified other than MEKK $\alpha$.

A model for the function of $M E K K \alpha$ is shown in Figure 8. MEKK $\alpha$ is required for proper prespore cell patterning and maintaining cells in the prespore state of differentiation. In this model UBPB and UBCB differential ly control MEKK $\alpha$ degradation and/or processing and UBPB functions genetically to potentiate prespore cell differentiation. MEKK $\alpha$ is required for patterning and developmental timing, but its degradation may al so be required for the initiation of culmination. This is reminiscent of the regulation of cyclins during mitosis. Cyclins are required to pass through a stage but must be later degraded by ubiquitin-directed proteolysis (Surana et al. 1991; Amon et al. 1994; Seufert et al. 1995; A mon 1997). The regulation of $\mathrm{MEKK} \alpha$ may have direct parallels to that of cyclins during the cell cycle, whereby the temporal and spatial control of MEKK $\alpha$ function is mediated partially through its degradation.

\section{Materials and methods}

Cell culture and development

The wild-type Dictyostelium cells, strain KAx-3, were grown and transformed using standard techniques (N ellen et al. 1987). Clonal isolates of non-drug-resistant strains were selected by plating clonally on SM plates in association with Klebsiella aerogenes as a food source. Clonal isolates carrying MEKK $\alpha$ expression constructs were transformed using G 418 as a sel ectable marker and clonal isolates were selected on DM plates in association with Escherichia coli $\mathrm{B} / \mathrm{r}$ carrying neomycin resistance (Hughes et al . 1992). M orphology was examined by plating cells at different densities on nonnutrient agar plates containing $12 \mathrm{~mm} \mathrm{Na} / \mathrm{KPO}_{4}(\mathrm{pH} \mathrm{6.1})$.

\section{Molecular biology}

Polymerase chain reaction (PCR) cloning of MEKK $\alpha$ was performed using sense [GA(A/G)(C/T)TIATGGCIGTIAA $(A / G) C$ ] and antisense [TTIGCICC(T/C)TTIAT(A/G)TCI C(G/T)(A/ G)TG] degenerate primers to prime genomic DNA of $K A x-3$. Using one of the PCR products as a probe, a $\lambda$ ZAP CDN A library was screened as described previously (Schnitzler et al. 1994) and cDNA clones were isolated and sequenced. The plasmid for homologous recombination was constructed by insertion of the Dictyostelium THY 1 gene cassette into the MEKK $\alpha$ open reading frame (ORF) at the Pvull site located 1136 bp downstream from the start codon of MEKK $\alpha$ CDNA subcloned into pSP72 (Xhol/BgllI). This construct was linearized with Xhol and EcoRV, electroporated into the thymidine auxotrophic strain $\mathrm{JH} 10$, and transformants were selected and screened for disruption of the MEKK $\alpha$ by genomic DN A blot analysis as described previously (N ellen et al. 1987). T ransformants were sel ected and screened for disruption of the gene encoding MEKK $\alpha$ by Southern blot analysis. Site-directed mutagenesis to create a dominant-negative mutant of MEKK $\alpha$ was performed using the Transformer Site Directed M utagenesis Kit from Clontech with mutation primer (5'-TTTGCTGTTGCACAATTAGAAATCG$\left.3^{\prime}\right)$. The construct containing site-directed mutants was sequenced to confirm the nucleotide substitutions and the ab-

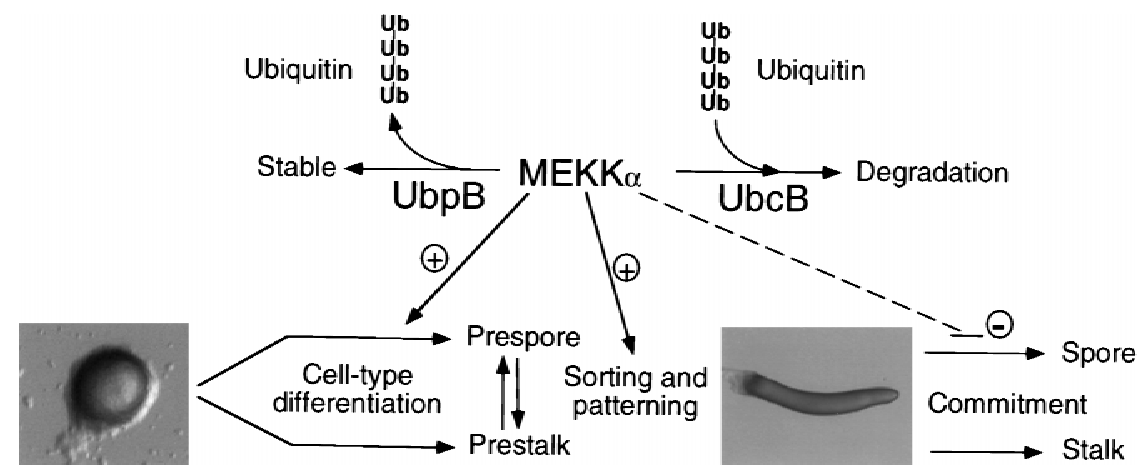

from entering terminal differentiation, resulting in delayed development and abnormal patt control temporal and spatial activity of MEKK $\alpha$ differentially by degradation and/or processing and UBPB functions genetically to potentiate prespore cell differentiation. Whether this is solely through its effect on MEKK $\alpha$ or by controlling other proteins as well is not known. Down-regulation of MEKK $\alpha$ activity via ubiquitination through UBCB and ubiquitin-dependent proteolysis may be important for terminal differentiation.

Figure 8. Model for MEKK $\alpha$ function. MEKK $\alpha$ is required for normal prespore cell-type differentiation and sorting and/or patterning of prestalk and prespore cells as reflected in the phenotypes of null cells, cells expressing MEKK $\alpha^{N}$, and cells overexpressing MEKK $\alpha$ in which there is a loss of the distinct boundaries between the prestalk and prespore domains. MEKK $\alpha$ is also required for maintaining the prespore state, as suggested by the developmental propensity of mek $\alpha^{-}$cells to differentiate into prestalk cells in chimeras. Overexpression of MEKK $\alpha^{-}$in prespore cells keepscells patterning. We propose that UBPB and UBCB 
sence of other mutations. RNA blots were done as described previously ( $M$ ann et al. 1987). All MEKK $\alpha$ constructs were expressed in Dictyostelium as stable G418-resistant transformants downstream from the Act15, Discoidin, prespore-specific SP60, or prestalk-specific ecmA promoters as described previously (Dynes et al. 1994). For the expression of myc-tagged WD40 in the pDXA3C vector, PCR was done with sense (5'-GTTTTGGATCCAAAATGGCAACAGCACAACCACCATGGT-3') and antisense (5'-GTTTTCTCGAGTATCAATACTCCAAATTTTTACAAGTTTATC-3'). The PCR product was cut with BamHI/Xhol and subcloned into a PDXA-3C vector carrying a myc-epitope sequence. Flag-tagged MEKK $\alpha$ was created by performing PCR with sense (5'-GTTTTAGATCTAAAATGGACTACAAGGACGATGACAAGATGTCATGGTTGAATAATCCTTCTC-3') and antisense (5'-CTTGTGACATATGTGA TGGTATATTTG-3') primers. The PCR product was cut with BamHI/ $\mathrm{Ncol}$ and ligated into pDXA-3C in association with an $\mathrm{Ncol} / \mathrm{Xhol}$ fragment of $M E K K \alpha^{D N}$. The plasmid for homologous recombination of UBPB was constructed by insertion of a blasticidin-resistance gene cassette into the UBPB ORF at the AfIIII site. This construct was linearized with EcoRI and EcoRV, electroporated into the KAx-3 strain, and transformants were selected and screened for disruption of the UBPB by genomic DN A blot analysis. MEKK $\alpha$ and MEKK $\alpha \Delta$ WD overexpression constructs were made by cloning the Xhol or Xhol/Clal fragment of a 3-1 cDNA clone into DIP-a.

\section{Analysis of morphology and $\beta$-galactosidase staining}

Cells grown to mid-log phase in shaking cultures of HL5 medium were washed in $12 \mathrm{~mm} \mathrm{Na/KPO}$ buffer (pH 6.1), resuspended in phosphate buffer at $2 \times 10^{7}$ cells, and spread on nonnutrient plates for development. For $\beta$-galactosidase staining, cells were developed on nitrocellulose filters resting on top of nonnutrient plates and then stained as described previously (Mann et al. 1994).

\section{Screening of the yeast two-hybrid system}

The yeast two-hybrid system developed in the laboratory of Roger Brent was used and screened as described previously (Gyuris et al. 1993; Lee et al. 1997). An Ncol/Xhol fragment of MEKK $\alpha$ was subcloned into pEG202, a bait vector. Approximately $0.8 \times 10^{6}$ independent library clones were obtained and screened for a $\beta$-galactosidase activity. $\mathrm{N}$ ine positive clones were obtained after the primary and secondary screenings.

Western blot and indirect immunofluorescence staining

Cells harvested at various developmental time points were washed, solubilized with lysis buffer (20 mM Tris at $\mathrm{pH} 6.8,1 \%$ SDS, $1 \mathrm{~mm}$ EDTA, $1 \mathrm{~mm} \mathrm{PMSF}$ ), and heated at $100^{\circ} \mathrm{C}$ for $5 \mathrm{~min}$. The protein content of each extract was measured with the BioRad protein assay kit. Twenty micrograms of protein per lane were resolved on either $8 \%$ or $10 \%$ gels, transferred onto PVDF membrane, and blots were processed by standard procedures (Harlow and Lane 1988). Bound antibody was detected with the ECL Western blotting kit (Amersham). Monoclonal anti-myc antibody, 9E10, was a generous gift of Beverly Errede (University of N orth Carolina, Chapel Hill). Monoclonal antiFlag antibody was obtained from Kodak. For immunofluorescence staining, cells were starved in $12 \mathrm{~mm}$ sodium phosphate buffer ( $\mathrm{pH}$ 6.2) for $>5 \mathrm{hr}$ and fixed with $4 \%$ formal dehyde for 5 min. Cells were permeabilized with $0.5 \%$ Triton X-100, washed, and incubated with $1.4 \mu \mathrm{g} / \mathrm{ml}$ anti-FLAG monoclonal antibody in PBS containing $0.5 \%$ BSA and $0.05 \%$ Tween-20 for $1 \mathrm{hr}$. Cells were washed in 0.5\% BSA containing PBS and incubated with FITC-labeled anti-mouse antibodies for $1 \mathrm{hr}$. After washing, cells were observed with a $60 \times$ oil immersion lens on a N ikon M icrophot-FX microscope. Images were captured with a Photometrics Sensys camera and IP Lab Spectrum software. The GenBank accession number for MEKK $\alpha$ (mkka) is AF093689 and for ubpB is AF093690.

\section{Acknowledgments}

We are indebted to Randy Hampton (University of California at San Diego) for valuable discussions on ubiquitin-mediated protein degradation, and to Beverly Errede (University of N orth Carolina) and Laurence Aubry and Jason Brown (UCSD), for hel pful discussions and reading the manuscript critically. This work was supported by U.S. Public Health Service grants to R.A.F.

The publication costs of this article were defrayed in part by payment of page charges. This article must therefore be hereby marked 'advertisement' in accordance with 18 USC section 1734 solely to indicate this fact.

\section{References}

A be, K. and K. Yanagisawa. 1983. A new class of rapid developing mutants in Dictyostelium discoideum: Implications for cyclic AM P metabolism and cell differentiation. Dev. Biol. 95: 200-210.

Abe, T., A. Early, F. Siegert, C. Weijer, and J. Williams. 1994. Patterns of cell movement within the Dictyostelium slug reveal ed by cell type-specific, surface labeling of living cells. Cell 77: 687-699.

Amon, A. 1997. Regulation of B-type cyclin proteolysis by Cdc28-associated kinases in budding yeast. EMBO J. 16: 2693-2702.

Amon, A., S. Irniger, and K. N asmyth. 1994. Closing the cell cycle circle in yeast: $\mathrm{G} 2$ cyclin proteolysis initiated at mitosis persists until the activation of $\mathrm{Gl}$ cyclins in the next cycle. Cell 77: 1037-1050.

Araki, T., M. Gamper, A. Early, M. Fukuzawa, Y. A be, T. Kawata, E. Kim, R.A. Firtel, and J.G. Williams. 1998. Developmentally and spatially regulated activation of a Dictyostelium STAT protein by a serpentine receptor. EMBO J. 17: 4018-4028.

Bai, C., P. Sen, K. Hofmann, L. M a, M. Goebl, J.W. Harper, and S.J. Elledge. 1996. SKP1 connects cell cycle regulators to the ubiquitin proteolysis machinery through a novel motif, the F-box. Cell 86: 263-274.

Bal int-Kurti, P., G. Ginsberg, O. Rivero-Lezcano, and A. R. Kimmel. 1997. rZIP, a RING-leucine zipper protein that regulates cell fate determination during Dictyostelium development. Development 124: 1203-1213.

Bretschneider, T., B. Vasiev, and C.J. Weijer. 1997. A model for cell movement during Dictyostelium mound formation. J. Theor. Biol. 189: 41-51.

Chen, M., R. Insall, and P. Devreotes. 1996. Signaling through chemoattractant receptors in Dictyostelium. Trends Genet. 12: 52-57.

Ciechanover, A. 1994. The ubiquitin-proteasome proteolytic pathway. Cell 79: 13-21.

Clark, A., A. Nomura, S. Mohanty, and R.A. Firtel. 1997. A ubiquitin-conjugating enzyme is essential for developmental 
transitions in Dictyostelium. Mol. Biol. Cell 8: 1989-2002.

Dynes, J.L., A.M. Clark, G. Shaulsky, A. Kuspa, W.F. Loomis, and R.A. Firtel. 1994. LagC is required for cell-cell interactions that are essential for cell-type differentiation in Dictyostelium. Genes \& Dev. 8: 948-958.

Early, A., T. A be, and J. Williams. 1995. Evidence for positional differentiation of prestalk cells and for a morphogenetic gradient in Dictyostelium. Cell 83: 91-99.

Early, A.E., M.J. Gaskell, D. Traynor, and J.G. Williams. 1993. Two distinct populations of prestalk cells within the tip of the migratory Dictyostelium slug with differing fates at culmination. Development 118: 353-362.

Firtel, R.A. 1995. Integration of signaling information in controlling cell- fate decisions in Dictyostelium. Genes \&Dev. 9: 1427-1444.

Firtel, R.A. 1996. Interacting signaling pathways controlling multicellular development in Dictyostelium. Curr. Opin. Genet. Dev. 6: 545-554.

Gaskins, C., M. M aeda, and R.A. Firtel. 1994. Identification and functional analysis of a developmentally regulated extracelIular signal-regulated kinase gene in Dictyostelium discoideum. Mol. Cell. Biol. 14: 6996-7012.

Gaskins, C., A.M. Clark, L. Aubry, J.E. Segall, and R.A. Firtel. 1996. The Dictyostelium MAP kinase ERK2 regulates multiple, independent developmental pathways. Genes \&Dev. 10: 118-128.

Ginsburg, G.T. and A.R. Kimmel. 1997. Autonomous and nonautonomous regulation of axis formation by antagonistic signaling via 7-span cAMP receptors and GSK3 in Dictyostelium. Genes \& Dev. 11: 2112-2123.

Ginsburg, G.T., R. Gollop, Y.M. Yu, J.M. Louis, C.L. Saxe, and A.R. Kimmel. 1995. The regulation of Dictyostelium development by transmembrane signalling. J. Euk. Microbiol. 42: 200-205.

Gyuris, J., E. Golemis, H. Chertkov, and R. Brent. 1993. Cdi1, a human $\mathrm{Gl}$ and $\mathrm{S}$ phase protein phosphatase that associates with Cdk2. Cell 75: 791-803.

Haberstroh, L. and R.A. Firtel. 1990. A spatial gradient of expresssion of a CAMP-regulated prespore cell type-specific gene in Dictyostelium. Genes \& Dev. 4: 596-612.

Han, Z. and R.A. Firtel. 1998. The homeobox-containing gene Wariai regulates anterior-posterior patterning and cell-type homeostasis in Dictyostelium. Development 125: 313-325.

Harlow, E. and D. Lane. 1988. Antibodies: A laboratory manual. Cold Spring Harbor Laboratory, Cold Spring Harbor, NY.

Harwood, A.J., S.E. Plyte, J. Woodgett, H. Strutt, and R.R. Kay. 1995. Glycogen synthase kinase 3 regulates cell fate in Dictyostelium. Cell 80: 139-148.

Hochstrasser, M. 1995. U biquitin, proteasomes, and the regulation of intracellular protein degradation. Curr. Biol. 7: 215223.

Hochstrasser, M. 1996. Ubiquitin-dependent protein degradation. Annu. Rev. Genet. 30: 405-439.

Hughes, J.E., G.J. Podgorski, and D.L. Welker. 1992. Selection of Dictyostelium discoideum transformants and analysis of vector maintenance using live bacteria resistant to G418. Plasmid 28: 46-60.

Kawata, T., A. Shevchenko, M. Fukuzawa, K.A. Jermyn, N.F. Totty, N.V. Zhukovskaya, A.E. Sterling, M. Mann, and J.G. Williams. 1997. SH2 signaling in a lower eukaryote: A STAT protein that regulates stalk cell differentiation in Dictyostelium. Cell 89: 909-916.

Kay, R.R. 1992. Cell differentiation and patterning in Dictyostelium. Curr. Opin. Cell Biol. 4: 934-938.

Krefft, M., L. Voet, J.H. Gregg, and K.L. Williams. 1985. Use of a monoclonal antibody recognizing a cell surface determinant to distinguish prestalk and prespore cells of Dictyostelium discoideum slugs. J. Embryol. Exp. Morphol. 88: 1524.

Lee, S., R. Escalante, and R.A. Firtel. 1997. A RAS GAP is essential for cytokinesis and spatial patterning in Dictyostelium. Development 124: 983-996.

Loomis, W.F. 1982. The development of Dictyostelium discoideum.Academic Press, New York, NY.

- - 1993. The development of Dictyostelium discoideum. Curr. Top. Dev. Biol. 28: 1-46.

Ma, H., M. Gamper, C. Parent, and R.A. Firtel. 1997. The Dictyostelium MAP kinase kinase DdMEK1 regulates chemotaxis and is essential for chemoattractant-mediated activation of guanylyl cyclase. EMBO J. 16: 4317-4332.

Mann, S.K.O., S. Datta, P. Howard, A. Hjorth, C. Reymond, C.M. Silan, and R.A. Firtel. 1987. Cyclic AMP regulation of gene expression during Dictyostelium devel opment. In Molecular approaches to devel opmental biology (ed. R.A. Firtel and E.H. Davidson), pp. 303-328. A.R. Liss, N ew York, NY.

Mann, S.K.O., P.N . Devreotes, S. Eliott, K. Jermyn, A. Kuspa, M. Fechheimer, R. Furukawa, C.A. Parent, J. Segall, G. Shaulsky, P.H. Vardy, J. Williams, K.L. Williams, and R.A. Firtel. 1994. Cell biological, molecular genetic, and biochemical methods to examine Dictyostelium. In Cell biology: A laboratory handbook (ed. J.E. Celis), pp. 412-451. Academic Press, San Diego, CA.

Mann, S.K.O., J.M. Brown, C. Briscoe, C. Parent, G. Pitt, P.N Devreotes, and R.A. Firtel. 1997. Role of cAM P-dependent protein kinase in controlling aggregation and post-aggregative devel opment in Dictyostelium. Dev. Biol. 183: 208-221.

Nellen, W., S. Datta, C. Reymond, A. Sivertsen, S. Mann, T. Crowley, and R.A. Firtel. 1987. M olecular biology in Dictyostelium: Tools and applications. Meth. Cell Biol. 28: 67-100.

Raper, K.B. 1940. Pseudoplasmodium formation and organization in Dictyostelium discoideum. J. Elisha Mitchell Sci. Soc. 56: 241-282.

Reymond, C.D., P. Schaap, M. Veron, and J.G. Williams. 1995. Dual role of CAMP during Dictyostelium development. Experientia 51: 1166-1174.

Schnitzler, G.R., C. Briscoe, J.M. Brown, and R.A. Firtel. 1995. Serpentine cAMP receptors may act through a $G$ proteinindependent pathway to induce postaggregative development in Dictyostelium. Cell 81: 737-745.

Schnitzler, G.R., W.H. Fischer, and R.A. Firtel. 1994. Cloning and characterization of the G-box binding factor, an essential component of the developmental switch between early and late development in Dictyostelium. Genes \&Dev. 8: 502514.

Segal I, J.E., A. Kuspa, G. Shaulsky, M. Ecke, M. M aeda, C. Gaskins, and R.A. Firtel. 1995. A MAP kinase necessary for receptor-mediated activation of adenylyl cyclase in Dictyostelium. J. Cell Biol. 128: 405-413.

Seufert, W., B. Futcher, and S. Jentsch. 1995. Role of a ubiquitinconjugating enzyme in degradation of S- and M-phase cyclins. Nature 373: 78-81.

Siegert, F. and C.J. Weijer. 1995. Spiral and concentric waves organize multicellular Dictyostelium mounds. Curr. Biol. 5: 937-943.

Simon, M.N., O. Pelegrini, M. Veron, and R.R. Kay. 1992. Mutation of protein kinase-A causes heterochronic development of Dictyostelium. Nature 356: 171-172.

Skowyra, D., K.L. Craig, M. Tyers, S.J. Ell edge, and J.W. Harper. 1997. F-box proteins are receptors that recruit phosphorylated substrates to the SCF ubiquitin-ligase complex. Cell 91: 209-219. 


\section{Chung et al.}

Sternfeld, J. 1992. A study of pstB cells during Dictyostelium migration and culmination reveals a unidirectional cell type conversion process. Wm. Roux Arch. Dev. Biol. 201: 354363.

Surana, U., H. Robitsch, C. Price, T. Schuster, I. Fitch, A. Futcher, and K. N asmyth. 1991. The role of CDC28 and cyclins during mitosis in the budding yeast $\mathrm{S}$. cerevisiae. Cell 65: 145-161.

Thomas, D., L. Kuras, R. Barbey, H. Cherest, P.L. Blai seau, and Y. Surdin-Kerjan. 1995. Met30p, a yeast transcriptional inhibitor that responds to S-adenosylmethionine, is an essential protein with WD40 repeats. Mol. Cell Biol. 15: 65266534.

Varshavsky, A. 1997. The ubiquitin system. Trends Biochem. Sci. 22: 383-387.

Williams, J. 1995. Morphogensis in Dictyostelium: N ew twists to a not-so-old tale. Curr. O pin. Genet. Dev. 5: 426-431. 


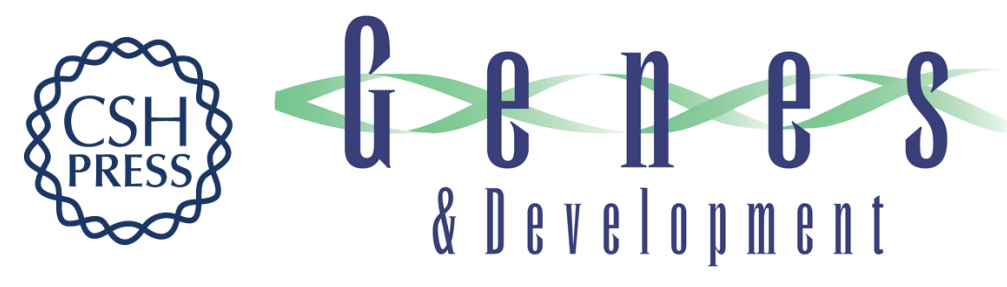

\section{A novel, putative MEK kinase controls developmental timing and spatial patterning in Dictyostelium and is regulated by ubiquitin-mediated protein degradation}

Chang Y. Chung, T.B.K. Reddy, Kemin Zhou, et al.

Genes Dev. 1998, 12:

Access the most recent version at doi:10.1101/gad.12.22.3564

References This article cites 47 articles, 17 of which can be accessed free at: http://genesdev.cshlp.org/content/12/22/3564.full.html\#ref-list-1

License

Email Alerting

Service right corner of the article or click here.

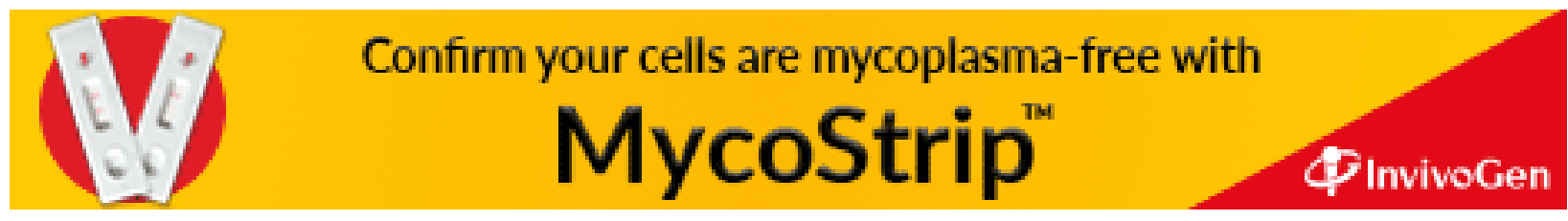

